\title{
КОМПЛЕКСНЫЙ АНАЛИЗ ФОСФАТНЫХ ПОКРЫТИЙ И ШЛАМОВ
}

\author{
Kaia TONSUAADU, M. VEIDERMA, Rutt TAKKIN, Katalin NEMES. FOSFAATKATETE JA -SLAM- \\ MIDE KOMPLEKSANALOUS \\ Kaia TYNSUAADU, M. VEIDERMA, Rutt TAKKIN, Katalin NEMES. COMPLEX ANALYSIS OF \\ PHOSPHATE COATINGS AND SLUDGES
}

Для защиты металлов от коррозии широко применяется фосфатирование ['], при этом фосфатный слой обычно наносится на металл под лакокрасочное покрытие. Защитный слой образуется на поверхности металла при контакте с раствором, в котором содержится фосфорная кислота, ионы металлов $\left(\mathrm{Zn}^{2+}, \mathrm{Mn}^{2+}, \mathrm{Fe}^{2+}\right.$ и др.) и окислителей $\left(\mathrm{NO}_{3}^{-}\right.$, $\mathrm{NO}_{2}^{-}, \mathrm{ClO}_{3}^{-}$или $\mathrm{H}_{2} \mathrm{O}_{2}$ ). Образование труднорастворимых фосфатов на поверхности металла является процессом электрохимическим: металл реагирует со свободной фосфорной кислотой, выделяется водород, а однозамещенные фосфаты переходят в более основные, обычно в трехзамещенные, химически связанные с металлом. При этом возможно образование двойных фосфатов. Часть фосфатов осаждается из раствора в виде шлама.

Противокоррозионные и адгезионные свойства фосфатного покрытия во многом определяются его химическим составом, зависящим от условий фосфатирования (состава раствора, температуры, времени, подготовки поверхности металла и др.) [2].

Для изучения химизма фосфатирования в целях совершенствования процесса необходимо определение состава покрытия, а также образующихся шламов.

В данной работе объектами исследования служили фосфатные покрытия на стали (M2 X) и высушенные шламы. Фосфатирование стали осуществляли по методике [3] погружением образцов в растворы фосфатов цинка и марганца, условия процесса приведены в табл. 1.

Для селективного растворения покрытия разработана методика, по которой образцы обрабатывали $0,2 \mathrm{M}$ раствором $\mathrm{NaOH}$, содержащим $2 \%$ динатриевой соли этилендиаминтетрауксусной кислоты и $2 \%$ тартрата калия-натрия (рН 13), при $80^{\circ} \mathrm{C}$ в течение 30 мин. Шламы растворяли в растворе $\mathrm{HCl}(1: 1)$. Содержание $\mathrm{Zn}, \mathrm{Mn}$ и $\mathrm{Fe}$ в растворе определяли атомно-абсорбционным методом на приборе SP-9-700 фирмы «Pye Unicam» (Великобритания), содержание фосфора - фотоколориметрически по желтому фосфорномолибденовому комплексу. Точность определения в пределах $3 \%$ отн.

ИК-спектры поглощения снимали на приборе «Specord 75 IR» (ГДР) в интервале частот $400-2000 \mathrm{~cm}^{-1}$. Образцы готовили в виде таблеток, спрессованных из смеси покрытия, соскобленного с поверхности металла, и $\mathrm{KBr}$.

Рентгенограммы фосфатированной поверхности снимали на приборе «Дрон-0,5» с железным катодом (при 25-27 кВ, 7-12 мА). Для микроскопических исследований покрытий использовали электронный микроскоп «Tesla BS-300» (ЧССР).*

* Рентгенограммы сняты К. Утсалом; микроснимки сняты в лаборатории электронної микроскопии ТПИ У. Каллавус. 
Химический состав фосфатных покрытий и шламов при различных условиях фосфатирования

\begin{tabular}{|c|c|c|c|c|c|c|c|c|}
\hline \multirow{2}{*}{ Показатель } & \multicolumn{2}{|c|}{$\begin{array}{c}\mathrm{Zn-}-\mathrm{NO}^{-}{ }_{2}, \\
45^{\circ} \mathrm{C}, 5 \text { мин }\end{array}$} & \multicolumn{2}{|c|}{$\begin{array}{c}\mathrm{Zn}-\mathrm{ClO}_{-}^{-}, \\
70^{\circ} \mathrm{C}, 5 \text { мин }\end{array}$} & \multicolumn{2}{|c|}{$\begin{array}{c}\mathrm{Zn}, 25^{\circ} \mathrm{C} \text {, } \\
15 \text { мин }\end{array}$} & \multicolumn{2}{|c|}{$\begin{array}{l}\mathrm{Mn}, 72^{\circ} \mathrm{C}, \\
10 \text { мин }\end{array}$} \\
\hline & покрытие & шлам & покрытие & шлам & покрытие & шлам & покрытие & шлам \\
\hline \multicolumn{9}{|l|}{ Содержание, \% } \\
\hline $\begin{array}{l}\mathrm{P}_{2} \mathrm{O}_{5} \\
\mathrm{FeO} \\
\mathrm{MeO} \\
\mathrm{H}_{2} \mathrm{O}\end{array}$ & $\begin{array}{l}31,4 \\
17,5 \\
37,3 \\
-\end{array}$ & $\begin{array}{l}38,4 \\
22,2 \\
23,3 \\
16,4\end{array}$ & $\begin{array}{l}33,5 \\
21,2 \\
34,8 \\
-\end{array}$ & $\begin{array}{r}37,1 \\
32,9 \\
7,4 \\
22,5\end{array}$ & $\begin{array}{l}31,9 \\
22,4 \\
37,5 \\
-\end{array}$ & $\begin{array}{r}26,5 \\
27,6 \\
6,6 \\
-\end{array}$ & $\begin{array}{l}39,7 \\
16,8 \\
32,2 \\
-\end{array}$ & $\begin{array}{l}38,2 \\
17,9 \\
30,7 \\
14,9\end{array}$ \\
\hline \multicolumn{9}{|l|}{$\begin{array}{l}\text { Молярное } \\
\text { соотношение }\end{array}$} \\
\hline $\begin{array}{l}\mathrm{Fe}: \text { металл } \\
\text { (FеO +ме- } \\
\text { таллоксид): }\end{array}$ & 0,53 & 1,07 & 0,61 & 5,02 & 0,67 & 4,71 & 0,51 & 0,57 \\
\hline $\begin{array}{l}: \mathrm{P}_{2} \mathrm{O}_{5} \\
\text { Масса покры- }\end{array}$ & 3,18 & 2,20 & 3,08 & 2,10 & 3,44 & 2,49 & 2,46 & 2,53 \\
\hline 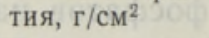 & 8,04 & - & 7,07 & - & 3,25 & - & 16,51 & - \\
\hline
\end{tabular}

На микроснимках поверхности металла (рис. 1) видна дендритовая структура кристаллов цинкфосфатного покрытия. Размеры фибрилл, образующих сферолиты, в среднем составляют 1-40 мкм. Покрытия, полученные в растворе с окислителями, по структуре более однородны, чем полученные без окислителя (рис. 1, а, б, в). В последнем случае видны центры роста кристаллов. Марганецфосфатный слой состоит из несимметричных гексагональных кристаллов размерами $3-8$ мкм (рис. $1, \Gamma)$.

Результаты химического анализа приведены в табл. 1. Молярное соотношение $\mathrm{Fe}: \mathrm{Zn}$ в цинкфосфатных покрытиях было 0,53-0,67, в шламax $1-5$, т. е. в 10 раз больше. Таким образом, покрытие состоит из фосфатов цинка и железа, а шлам представлен в основном фосфатами железа. В марганецфосфатном покрытии и шламе фосфатирования соотношение $\mathrm{Fe}: \mathrm{Mn}$ составляло 0,51 и 0,57 соответственно. Химический состав их близок к составу гераулита - $(\mathrm{Mn}, \mathrm{Fe})_{5} \mathrm{H}_{2}\left(\mathrm{PO}_{4}\right)_{4} \cdot 4 \mathrm{H}_{2} \mathrm{O}$.

Молярное соотношение $(\mathrm{FeO}+\mathrm{ZnO}): \mathrm{P}_{2} \mathrm{O}_{5}$ в цинкфосфатных покрытиях было более 3 , а в шламах от 2,2 до 2,5 . Из этого можно заключить, что в состав покрытия входят трехзамещенные фосфаты и избыток железа, а в шламах содержатся гидрофосфаты. Соотношение $(\mathrm{FeO}+$ $+\mathrm{MnO}): \mathrm{P}_{2} \mathrm{O}_{5}$ в марганецфосфатном покрытии 2,46, в шламе 2,53. В гераулите это соотношение равно 2,5.

ИК-спектры образцов также указывают на образование монофосфатов на поверхности металла (рис. 2). Интенсивные полосы поглощения при 570,630,950,1010-1030, $1110 \mathrm{~cm}^{-1}$ свидетельствуют о наличии в цинкфосфатном покрытии гопеита $\left(\mathrm{Zn}_{3}\left(\mathrm{PO}_{4}\right)_{2} \cdot 4 \mathrm{H}_{2} \mathrm{O}\right)\left[{ }^{4}\right]$, а дополнительные полосы при 990 и 1420-1440 cм$^{-1}$ - о содержании также других фосфатов. В спектрах шламов видны, кроме колебаний $\mathrm{PO}^{3-}{ }_{4}$, колебания $\mathrm{P}$-OН-связей при $800-900 \mathrm{~cm}^{-1}\left[{ }^{4}\right]$, что указывает на образование гидрофосфата. Марганецфосфатное покрытие и шлам, несмотря на близость химического состава, имеют, по данным ИК-спектров, разное строение.

На рентгенограммах цинкфосфатных покрытий (табл. 2) превалируют рефлексы гопеита $(d=9,04,4,57 \AA)$ [5], но имеются и рефлексы $(d=4,47,2,83,1,89 \AA)$, свидетельствующие о содержании двойного фос- 

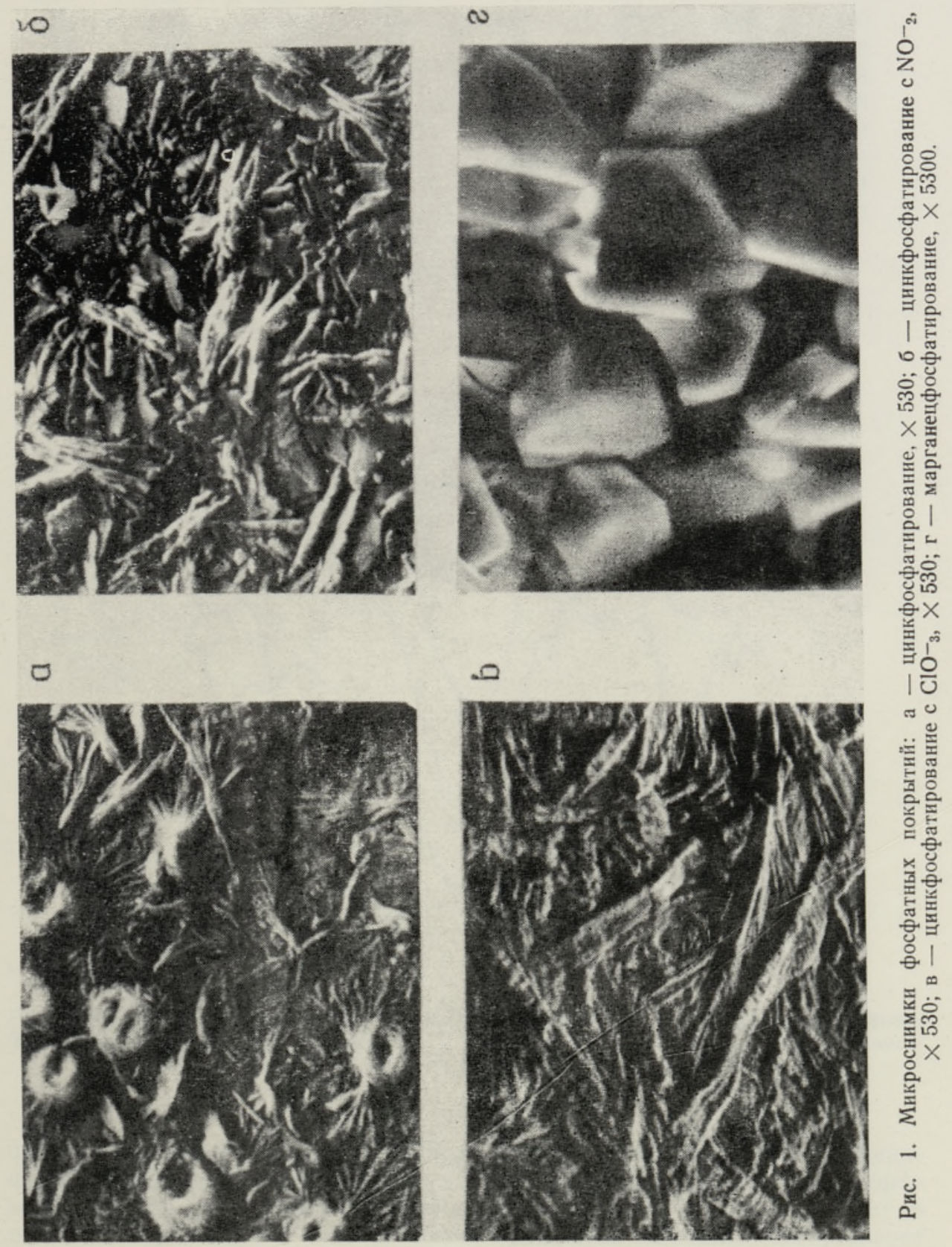
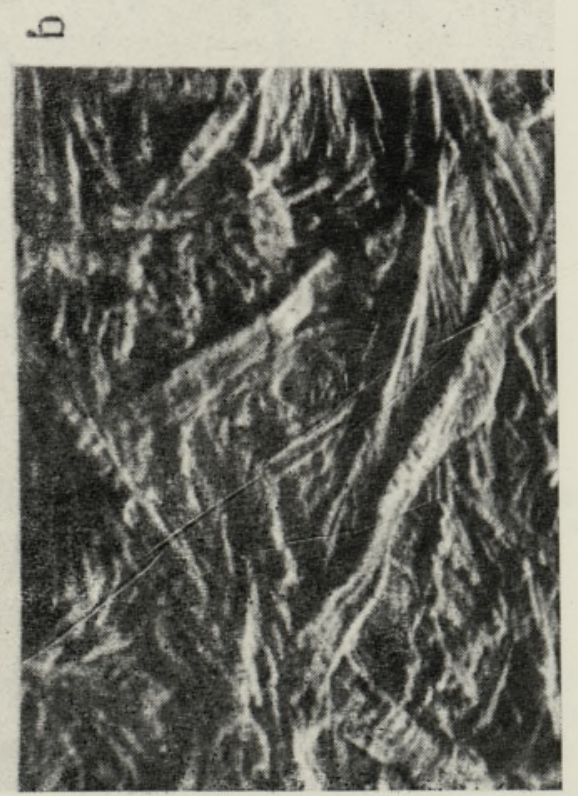

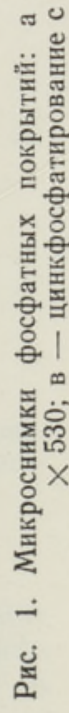



Рентгенографические данные цинкфосфатных покрытий и шлама

\begin{tabular}{|c|c|c|c|c|c|c|c|}
\hline \multicolumn{2}{|c|}{$\mathrm{Zn}-\mathrm{NO}^{-}{ }_{2}$} & \multicolumn{2}{|c|}{$\mathrm{Zn}-\mathrm{ClO}_{-}{ }_{3}$} & \multicolumn{2}{|c|}{$\mathrm{Zin}$} & \multicolumn{2}{|c|}{ Шлам-NO- } \\
\hline$d, \AA$ & $I / I_{0}, \%$ & $d, \AA$ & $I / I_{0}, \%$ & $d, \AA$ & $I / I_{0}, \%$ & $d, \AA$ & $I / I_{0}, \%$ \\
\hline 9,00 & 100 & 9,01 & 100 & 9,04 & 100 & 9,09 & 15 \\
\hline 4,58 & 70 & 4,56 & 30 & 4,57 & 25 & 7,86 & 100 \\
\hline 4,47 & 90 & 4,47 & 80 & 4,45 & 90 & 4,55 & 10 \\
\hline 3,39 & 30 & 3,40 & 30 & 3,40 & 15 & 3,92 & 50 \\
\hline 2,83 & 30 & 2,84 & 30 & 2,83 & 10 & 3,21 & 20 \\
\hline 2,612 & 10 & 2,618 & 10 & & & 2,942 & 10 \\
\hline 2,228 & 30 & 2,224 & 10 & 2,228 & 15 & 1,955 & 10 \\
\hline 1,899 & 10 & 1,896 & 8 & & & 1,930 & 10 \\
\hline 1,483 & 25 & 1,481 & 10 & 1,484 & 10 & 1,563 & 10 \\
\hline
\end{tabular}

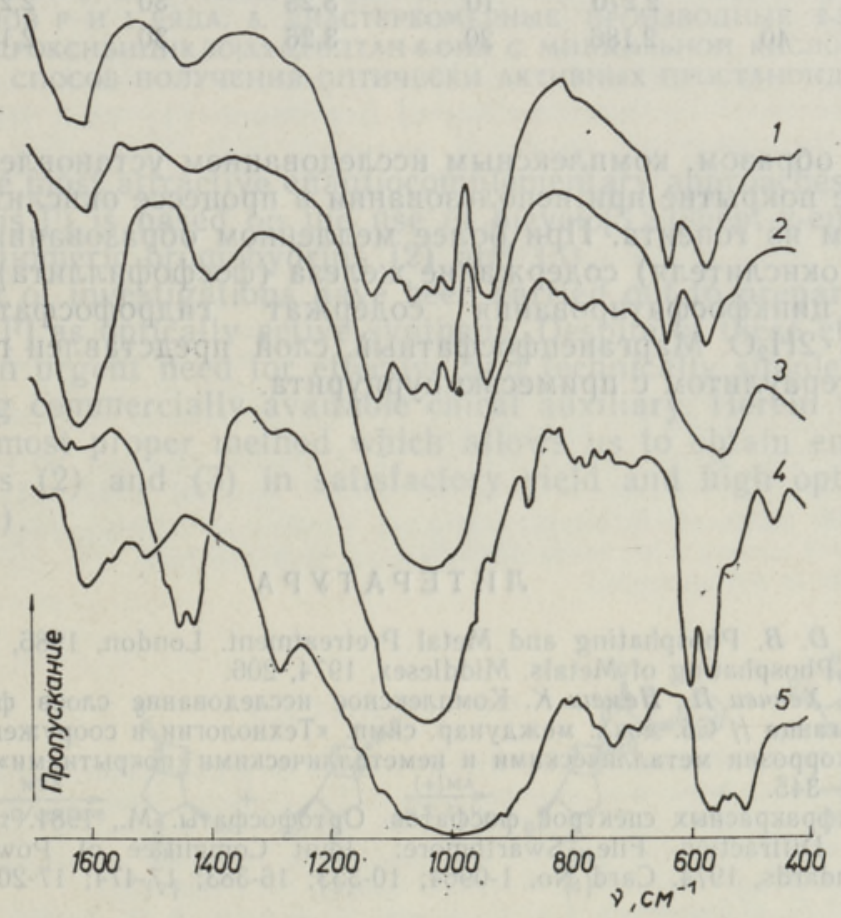

Рис. 2. ИК-спектры поглощения: 1 - цинкфосфатное покрытие (с $\mathrm{NO}_{2}$ ), 2 - цинкфосфатное покрытие (без окислителя), 3 - шлам цинкфосфатирования, 4 - марганецфосфатное покрытие, 5 - шлам марганецфосфатирования.

фата типа фосфофиллита $-\mathrm{Zn}_{2} \mathrm{Fe}\left(\mathrm{PO}_{4}\right)_{2} \cdot 4 \mathrm{H}_{2} \mathrm{O}$. В шламах цинкфосфатирования без окислителя и с $\mathrm{ClO}_{-}^{-}$содержится в основном аморфная фаза (по данным химического анализа, - гидрофосфаты железа), в шламе из раствора с $\mathrm{NO}_{2}^{-}$, кроме фосфатов железа, присутствует $\mathrm{Zn}_{3}\left(\mathrm{PO}_{4}\right)_{2} \cdot 2 \mathrm{H}_{2} \mathrm{O}(d=7,86,3,92,3,21 \AA)$ со следами гопеита.

Марганецфосфатный слой (табл. 3) состоит из гераулита $(d=3,15$, $2,987 \AA)$. Дифрактограмма шлама марганецфосфатирования соответствует гераулиту с примесью пурпурита - $(\mathrm{Fe}, \mathrm{Mn}) \mathrm{PO}_{4}\left[{ }^{5}\right]$. 
Рентгенографические данные марганецфосфатного покрытия и шлама

\begin{tabular}{r|r|r|r|r|r|r|r}
\hline \multicolumn{4}{c}{ Покрытие } & \multicolumn{4}{|c}{ Шлам } \\
\cline { 5 - 8 }$d, \AA$ & $I / I_{0}, \%$ & $d, \AA$ & $I / I_{0}, \%$ & $d, \AA$ & $I / I_{0}, \%$ & $d, \AA$ & $I / I_{0}, \%$ \\
\hline \multirow{2}{*}{8,72} & 45 & & & 8,83 & 30 & 3,20 & 50 \\
8,09 & 100 & 3,15 & 95 & 8,13 & 35 & 3,16 & 100 \\
6,33 & 15 & 3,07 & 20 & 6,34 & 7 & 3,08 & 25 \\
5,99 & 15 & & & 6,02 & 10 & 3,04 & 20 \\
& & 2,987 & 70 & 4,97 & 15 & 3,00 & 80 \\
4,71 & 40 & 2,873 & 60 & 4,72 & 25 & 2,886 & 40 \\
4,53 & 20 & & & 4,55 & 30 & 2,803 & 20 \\
4,37 & 5 & 2,625 & 25 & 4,39 & 40 & 2,634 & 30 \\
4,04 & 20 & 2,561 & 20 & 4,06 & 15 & 2,562 & 30 \\
3,64 & 15 & 2,427 & 15 & 3,65 & 20 & 2,437 & 20 \\
& & 2,270 & 10 & 3,28 & 30 & 2,273 & 15 \\
3,26 & 40 & 2,186 & 20 & 3,26 & 30 & 2,189 & 35
\end{tabular}

Таким образом, комплексным исследованием установлено, что цинкфосфатное покрытие при использовании в процессе окислителей состоит в основном из гопеита. При более медленном образовании фосфатного слоя (без окислителя) содержание железа (фосфофиллита) в нем выше. Шламы цинкфосфатирования содержат гидрофосфат железа и $\mathrm{Zn}_{3}\left(\mathrm{PO}_{4}\right)_{2} \cdot 2 \mathrm{H}_{2} \mathrm{O}$. Марганецфосфатный слой представлен гераулитом, а шлам - гераулитом с примесью пурпурита.

\section{ЛИТЕ Р А Т Р А}

1. Freeman, D. B. Phosphating and Metal Pretreatment. London, 1986, 225.

2. Lorin, G. Phosphating of Metals. Middlesex, 1974, 206.

3. Габор Т., Хенчеи П., Немеш К. Комплексное исследование слоев фосфата цинка и марганца // Сб. докл. междунар. симп. «Технологии и сооружения для зашиты от коррозии металлическими и неметаллическими покрытиями». Албена, 1986, $341-345$.

4. Атлас инфракрасных спектров фосфатов. Ортофосфаты. М., 1981.

5. Powders Diffraction File. Swarthmore: Joint Committee of Powder Diffraction Standards, 1974. Card No. 1-0964; 10-333; 16-383; 17-474; 17-202.

таллинский политехнический институт Поступила в редакцию 7/XII 1988

Будапеитский технический университет 